\title{
Avaliação da técnica de vitrificação de ovários de camundongos da linhagem B6D2F1, pertencentes ao Instituto de Ciência e Tecnologia em Biomodelos - ICTB/Fiocruz-RJ
}

[Evaluation of ovary vitrification technique from B6D2F1 strain belonging to the Institute of Biomodels Science and Technology ICTB / Fiocruz-RJ]

C.M.F. Sobrinho ${ }^{1}$, F.B. Knackfuss ${ }^{2}$, P.C.S. Souza ${ }^{1}$, T.M. Torres ${ }^{1}$, A.A. Ramos $^{1}$, L.P.B. Dias ${ }^{1}$, J.B.P. Ferreira ${ }^{1}$, I.M.F. Pires ${ }^{1}$

${ }^{1}$ Instituto de Ciências em Biomodelos e Tecnologia em Biomodelos - Fiocruz - Rio de janeiro, RJ

${ }^{2}$ Universidade do Grande Rio - Duque de Caxias, RJ

\section{RESUMO}

Objetivou-se testar a vitrificação de ovários de camundongos do ICTB/Fiocruz. Inicialmente, fez-se coleta e maturação in vitro dos oócitos de ovários a fresco e vitrificados, bem como avaliação de estruturas no cultivo embrionário, pós-fertilização in vitro. Fêmeas B6D2F1 foram eutanasiadas para remoção dos ovários $(n=60)$ e divididas em três grupos: grupo 1 (n=30 animais) - oócito de ovários vitrificados, maturados e fertilizados in vitro (120 fragmentos); grupo $2(n=15)$ (controle 1) - oócitos coletados a fresco, maturados e fertilizados in vitro; e grupo $3(\mathrm{n}=15)$ (controle 2) - oócitos maturados in vivo e fertilizados in vitro. A técnica foi verificada no desenvolvimento embrionário in vitro, que foi avaliado pelo teste de qui-quadrado (BioStat 5.0). Recuperaram-se 123, 224 e 328 oócitos nos G1, G2 e G3, respectivamente. Observaram-se diferenças significativas nas taxas de clivagem às 24 horas (embriões $\geq 2$ células) entre G1 $(8 \%)$ e G2 $(32 \%)(\mathrm{P}<0,1)$ e G1 e G3 $(49 \%)(\mathrm{P}<0,05)$, mas não entre G2 e G3 $(\mathrm{P}>0,05)$. Para blastocistos, às 96 horas, os grupos G1, G2 e G3 apresentaram, respectivamente, $6 \%, 11 \%$ e $46 \%$, diferindo significativamente entre eles $(\mathrm{P}<0,05)$. A vitrificação de ovários, a maturação oocitária e a fertilização in vitro são alternativas para a produção de embriões de camundongos in vitro.

Palavras-chave: vitrificação, murino, maturação, fertilização in vitro, embrião

\begin{abstract}
This work aimed test ovarian vitrification of hybrid mouse from ICTB/Fiocruz. Protocol collection and oocyte in vitro maturation from fresh and vitrified ovaries was established and embryos were evaluated after fertilization. B6D2F1 females were euthanized for ovarian removal $(n=60)$ and divided into 3 groups: $G 1(n=30)$ - ovaries fragmented $(n=120)$, vitrified, matured and fertilized; $G 2(n=15)$ - in vitro fertilization of oocytes matured in vitro from fresh ovaries; $G 3(n=15)$ - ampulla region oocytes in vitro fertilizated. Viability was verified by thawing, oocyte in vitro maturation and fertilization. In vitro embryo development of each group was evaluated by Chi-square test (BioStat 5.0). 123, 224 and 328 oocytes were recovered from $G 1, G 2$ and G3, respectively. Significant differences were observed in cleavage rates at 24 hours (embryos with 2 cells or more) between $G 1(8 \%)$ and $G 2(32 \%)(P<0.1)$ and $G 1$ and $G 3(49 \%)(P<0.05)$ but not between $G 2$ and $G 3(P>0.05)$. Blastocysts at 96 hours presented 6\%, 11\% and $46 \%$, respectively for $G 1, G 2$ and G3, differing significantly $(P<0.05)$. Ovary vitrification, oocyte in vitro maturation and in vitro fertilization were available for the production of in vitro mouse embryos.
\end{abstract}

Keywords: ovary vitrification, mouse, in vitro maturation and in vitro fertilization, embryo

Recebido em 10 de julho de 2018

Aceito em 29 de maio de 2019

E-mail: cristiano.sobrinho@ fiocruz.br 


\section{INTRODUÇÃO}

O Instituto de Ciência e Tecnologia em Biomodelos - ICTB, unidade técnico-científica da Fundação Oswaldo Cruz, produziu em 2017 cerca de 70 mil animais para atender a demanda interna, bem como a de outras instituições governamentais. Entre os modelos animais, os roedores são os mais utilizados em pesquisas biomédicas, sendo o camundongo (Mus musculus) o de maior demanda. O surgimento de novas tecnologias em genética molecular tem possibilitado o desenvolvimento de novos modelos animais geneticamente modificados, favorecendo estudos básicos e aplicados (Onos et al., 2016). Atualmente, mais de 15 mil linhagens de camundongos estão disponíveis para pesquisa (Frajblat e Amaral, 2017). Contudo, a manutenção das características dessas linhagens é um ponto crucial dentro dos biotérios de criação e experimentação, haja vista que mutações podem ocorrer espontaneamente a cada geração.

Nesse contexto, bancos de germoplasma assumem um caráter estratégico nos biotérios, principalmente nos biotérios de criação, pois permitem salvaguardar o patrimônio genético, diminuindo o custo de criação e a manutenção do número de linhagens estocadas, bem como facilitam a importação e a exportação. A formação desses bancos baseia-se inicialmente na criopreservação, que consiste na conservação de células, tecidos ou órgãos por meio da diminuição da temperatura, de forma a cessar as reações metabólicas nas células, permitindo a estocagem por tempo indeterminado (Mullen; Critser, 2007; Amorim et al., 2011a).

Assim, a utilização de protocolos de criopreservação adequados a cada tipo celular ou tecido é de fundamental importância na implantação de bancos de germoplasma nos biotérios (Byers et al., 2006; Dinnyes et al., 1995). Espera-se que o processo de criopreservação não comprometa a viabilidade da célula ou do tecido. Contudo, a diminuição e o subsequente aumento na temperatura durante o resfriamento e o reaquecimento podem resultar em crioinjúrias e afetar a viabilidade (Mullen; Critser, 2007; Amorim et al., 2011b).

Estruturas em estado diploide são as mais preconizadas para o estabelecimento de bancos de germoplasma; assim, os embriões são a primeira escolha, porém as linhagens respondem de forma específica aos métodos de criopreservação, evidenciando que o genótipo influencia significativamente a sobrevivência in vitro dos embriões submetidos ao congelamento (Dinnyes et al., 1995; Byers et al., 2006). Contudo, gametas no estado haploide tornam-se, algumas vezes, a única alternativa para superar as dificuldades no congelamento embrionário de algumas linhagens (Sztein et al., 2010).

Com base em resultados variáveis de cultivo in vitro de embriões criopreservados de linhagens geneticamente modificadas do ICTB, torna-se necessário, para preservação do material genético, o estabelecimento de um protocolo de criopreservação adequado para o tecido ovariano como alternativa para salvaguardar o material genético desses animais. O objetivo do presente trabalho foi criopreservar tecido ovariano de camundongos de linhagem híbrida (B6D2F1) por meio da vitrificação.

\section{MATERIAL E MÉTODOS}

O experimento foi realizado no ICTB/Fiocruz e recebeu aprovação da Comissão de Ética no Uso de Animais (Ceua) da Fiocruz, sob o número LW-28/17 (aprovado em 25/09/2017) (Anexo 1). Fêmeas da linhagem híbrida B6D2F1(n=60), com sete a oito semanas de idade, foram divididas em três grupos: G1 $(\mathrm{n}=30)$ fecundação in vitro de oócitos maturados in vitro, provenientes de fragmentos de ovários submetidos à vitrificação; G2 $\quad(n=15) \quad-$ fecundação in vitro de oócitos maturados in vitro, provenientes de ovários coletados a fresco; e G3 $(\mathrm{n}=15)$ - fecundação in vitro de oócitos maturados in vivo. Machos híbridos B6D2F1 $(n=3)$, com sete a oito semanas de idade, foram utilizados como doadores de sêmen para fertilização in vitro, e machos vasectomizados $(n=5)$ para acasalamento natural, com o objetivo de induzir a ovulação e a maturação oocitária nas fêmeas do G3.

As fêmeas foram agrupadas em microisoladores, em número de cinco animais por grupo até o momento da sua utilização, e os machos individualmente. Foram realizadas três repetições por grupo. Foram administrados 7,5UI de gonadotropina coriônica equina (eCG) (Novormon $\left.^{\circledR} 5000 \mathrm{UI}\right)$, por via intraperitoneal, 
com auxílio da seringa de insulina 6,0 x 0,25mm (30G).

O G1 foi estimulado com gonadotropina coriônica equina (eCG), 46 horas antes da ovariectomia. As fêmeas foram eutanasiadas, e, por meio de deslocamento cervical, foi realizada a retirada dos ovários, que foram seccionados ao meio. Os fragmentos ovarianos foram depositados em gotas de $100 \mu \mathrm{L}$ de meio M2 $\left(\right.$ Sigma-Aldrich $\left.{ }^{\circledR}\right)$, previamente aquecidas. Em seguida, as hemimetades foram transferidas para gotas de $100 \mu \mathrm{L}$ de solução pré-vitrificação e, posteriormente, para vitrificação, conforme Behbahanian et al. (2013), modificado com SFB. Todas as etapas foram feitas em placas de Petri $100 \times 20 \mathrm{~mm}$. As hemimetades foram, então, colocadas em espátulas (Behbahanian et al., 2013). As amostras foram imediatamente mergulhadas em nitrogênio líquido, envasadas em palheta de $0,5 \mathrm{~mL}$ e mantidas em botijão de nitrogênio líquido até o momento da desvitrificação. Foi desvitrificado um total de 60 hemimetades (três repetições). As espátulas foram encostadas em gotas de $100 \mu \mathrm{L}$ de meio M2 (Sigma-Aldrich $®)$, conforme Behbahanian et al. (2013), modificado com SFB. Após a desvitrificação, as estruturas foram transferidas e mantidas em gotas $(100 \mu \mathrm{L})$ de meio M2 (SigmaAldrich $^{\circledR}$ ), a uma temperatura de $37^{\circ} \mathrm{C}$, até o momento da retirada dos oócitos para maturação in vitro.

No G2, o protocolo de estimulação hormonal eCG foi realizado dois dias antes da desvitrificação dos ovários do G1 para a sincronização dos grupos e a realização da maturação in vitro. As fêmeas do G2 foram eutanasiadas, e os ovários coletados conforme descrito no grupo G1. Os fragmentos ovarianos foram colocados em placa NUNC de quatro poços, contendo $500 \mu \mathrm{L}$ de meio M2 (SigmaAldrich $^{\circledR}$ ), previamente aquecido a $37^{\circ} \mathrm{C}$, em placa aquecedora. Em seguida, os folículos foram perfurados com auxílio de agulha $24 \mathrm{G} 3 / 4 \mathrm{e}$ pinça anatômica de dissecção ponta fina, para liberação dos oócitos inclusos. Sob microscópio estereoscópio com aumento de 80x, os oócitos foram recolhidos e transferidos, com auxílio de pipeta automática de $10 \mu \mathrm{L}$, para placa NUNC de quatro poços contendo $1000 \mu \mathrm{L}$ de meio M2 (Sigma-Aldrich ${ }^{\circledR}$ ).
Após serem coletados dos ovários do G1 e G2, os oócitos foram lavados duas vezes, em $1000 \mu \mathrm{L}$ de meio M2 (Sigma-Aldrich ${ }^{\circledR}$ ), e, por último, em $1000 \mu \mathrm{L}$ da solução de maturação, conforme Salehnia et al. (2013) modificado. A seguir, os oócitos foram transferidos para gotas de $50 \mu \mathrm{L}$ de meio de maturação, cobertos por $3 \mathrm{~mL}$ de Ovoil $^{\mathrm{TM}}$ - Culture Oil (Vitrolife ${ }^{\circledR}$ ), em placa de Petri ( $35 \times 10 \mathrm{~mm})$, e incubados por 16 horas, em estufa, com temperatura de $37^{\circ} \mathrm{C}$ e $5 \%$ de $\mathrm{CO}_{2}$. Foram colocados até 25 oócitos por gota.

Já as fêmeas do G3 receberam uma dose de 7,5UI de gonadotropina coriônica equina (eCG) (Novormon $^{\circledR}$ 5000UI) e, 46 horas depois, uma segunda dose, com 7,5UI de gonadotropina coriônica humana (hCG) (Chorulon ${ }^{\circledR}$ 5000UI), por via intraperitoneal; em seguida, foram acasaladas com machos vasectomizados. As fêmeas que apresentaram tampão vaginal após acasalamento com machos vasectomizados, (+/$12 \mathrm{~h}$ pós-acasalamento) foram eutanasiadas, por meio de deslocamento cervical, e, a seguir, foi realizada a coleta dos ovidutos. Os ovidutos foram colocados em placa NUNC contendo gota de $1000 \mu \mathrm{L}$ de meio M2 (Sigma-Aldrich ${ }^{\circledR}$ ), previamente aquecido a $37^{\circ} \mathrm{C}$, e rompidos na região da ampola, liberando os complexos cumulus-oócitos.

Em seguida, com o auxílio de uma pipeta automática de $100 \mu \mathrm{L}$, os complexos cumulusoophorus foram coletados e lavados duas vezes, em poços de $1000 \mu \mathrm{L}$ em meio M2 (SigmaAldrich $^{\circledR}$ ), a $37^{\circ} \mathrm{C}$, e, por último, em $1000 \mu \mathrm{L}$ de solução de fertilização (meio M16 suplementado com 3\% de albumina sérica bovina (BSA), previamente estabilizado em estufa com $5 \%$ de $\mathrm{CO}_{2}$ e $37^{\circ} \mathrm{C}$ ). Após a eutanásia por deslocamento cervical, machos $(n=3)$ em idade reprodutiva tiveram as caudas dos epidídimos e os ductos deferentes retirados via incisão abdominal e colocados em placa de Petri, para realização da coleta e capacitação do sêmen, conforme Cemib (Cryopreservation..., 2010).

Os oócitos dos três grupos (G1, G2 e G3) foram transferidos para gotas de $200 \mu \mathrm{L}$ de meio de FIV (meio M16 (Sigma-Aldrich ${ }^{\circledR}$ ) suplementado com $3 \%$ de albumina sérica bovina (BSA) (SigmaAldrich $\left.^{\circledR}\right)$ ), cobertas com $3 \mathrm{~mL}$ de Ovoil $^{\mathrm{TM}}$ Culture Oil $\left(\right.$ Vitrolife $\left.^{\circledR}\right)$, previamente equilibradas overnight em estufa de $\mathrm{CO}_{2}$, a $5 \%$, com $37^{\circ} \mathrm{C}$. Foram colocados, no máximo, 25 
oócitos por gota. Posteriormente, cada gota foi acrescida de $50 \mu \mathrm{L}$ de sêmen previamente capacitado e, então, elas foram incubadas em estufa a $37^{\circ} \mathrm{C}$, com $5 \%$ de $\mathrm{CO}_{2}$, por quatro horas, para que houvesse a fertilização.

Passado o período de quatro horas de FIV, os oócitos foram lavados, por duas vezes, em $1000 \mu \mathrm{L}$ de meio M2 (Sigma-Aldrich ${ }^{\circledR}$ ), na placa NUNC, previamente aquecido a $37^{\circ} \mathrm{C}$, para retirada dos espermatozoides. Em seguida, os possíveis zigotos foram lavados e cultivados conforme Cemib (Cryopreservation..., 2012). O cultivo embrionário foi realizado em estufa, a $37^{\circ} \mathrm{C}$, com $5 \%$ de $\mathrm{CO}_{2}$, durante 96 horas. A observação das estruturas embrionárias (embriões de duas células até blastocistos) foi realizada $24,48,72$ e 96 h após a fertilização. As estruturas esperadas pelo tempo de cultivo foram: Oh: zigoto (após fecundação in vitro/4h) início do cultivo; $24 \mathrm{~h}: \geq 2$ células; $48 \mathrm{~h}: \geq 4$ células; 72h: $\geq 8$ células; 96h: $\geq$ mórulas. Os dados de taxa de clivagem ( 24 horas) e taxa de blastocistos (96 horas) entre os diferentes tratamentos foram analisados utilizando-se a análise estatística pelo teste qui-quadrado, sendo testados os níveis de significância 1 e $5 \%$ (Biostat 5.0).

\section{RESULTADOS E DISCUSSÃO}

Foram coletados 123, 224 e 328 oócitos nos G1, G2 e G3, respectivamente. Alguns oócitos provenientes dos ovários vitrificados apresentavam morfologia com redução das células cumulus oophorus se distinguindo dos oócitos dos G2 e G3, nos quais a presença dessas células era abundante, contribuindo para as melhores taxas de fertilização e, consequentemente, um maior número de estruturas desenvolvidas em embriões. As taxas de desenvolvimento embrionário foram observadas com 24, 48, 72 e 96 horas após o início do cultivo in vitro. Para cada tempo, foram consideradas as estruturas embrionárias esperadas no respectivo período de desenvolvimento (Tab. 1).

Tabela 1. Número (n) e percentual (\%) de estruturas embrionárias observadas durante as 96h de cultivo in vitro do $\mathrm{G} 1, \mathrm{G} 2$ e $\mathrm{G} 3$

\begin{tabular}{lllc}
\hline & $\mathrm{G} 1(\mathrm{n} / \%)$ & $\mathrm{G} 2(\mathrm{n} / \%)$ & $\mathrm{G} 3(\mathrm{n} / \%)$ \\
\hline 0 hora (possíveis zigotos) & $123(100 \%)$ & $224(100 \%)$ & $328(100 \%)$ \\
24 horas $(\geq 2$ células) & $10(8 \%)$ & $71(32 \%)$ & $168(49 \%)$ \\
48 horas $(\geq 4$ células) & $6(5 \%)$ & $42(18 \%)$ & $152(46 \%)$ \\
72 horas $(\geq 8$ células) & $8(6 \%)$ & $38(16 \%)$ & $147(44 \%)$ \\
96 horas ( $\geq$ mórula) & $7(6 \%)$ & $25(11 \%)$ & $154(46 \%)$ \\
\hline
\end{tabular}

No G1, em 24 horas, encontraram-se $10(8 \%)$ embriões de duas células; já às 48 horas, foram encontrados 12 embriões desenvolvidos. Às 72 horas, encontraram-se seis $(5 \%)$ embriões de oito células e duas (2\%) mórulas. $\mathrm{Na}$ última avaliação, às 96 horas, houve um aumento das estruturas que se desenvolveram a blastocistos, um $(0,8 \%)$ de oito células, uma $(0,8 \%)$ mórula, seis $(5 \%)$ blastocistos iniciais (Tab. 2).

Segundo Salehnia et al. (2013), tecidos de ovários vitrificados têm seu oócito amadurecido mais lentamente em relação ao tecido a fresco. Os resultados do presente estudo diferiram dos alcançados por esses autores, que obtiveram, em seu trabalho, taxa de clivagem em embriões de duas células $(89 \% / 63,6 \%)$, oito células $(54,6 \% / 27,2 \%)$, mórula $(46,9 \% / 15,9 \%)$ e blastocisto $(40,9 \% / 11,36 \%)$, correspondentes aos grupos controle e vitrificados, respectivamente. Tal fato se deve, provavelmente, aos meios utilizados na vitrificação, no cultivo e mesmo à linhagem dos camundongos usada, que diferiram do presente estudo.

No G2, com 24 horas, obtiveram-se 62 (27\%) embriões com duas células e nove (4\%) embriões com quatro células. Em 48 horas, foram encontrados $49(21 \%)$ de duas células, 38 (16\%) de quatro células, dois $(0,8 \%)$ de oito células e duas $(0,8 \%)$ mórulas. Em relação às 72 horas, os resultados de desenvolvimento embrionário foram representados por oito embriões $(4 \%)$ de oito células, 25 (11\%) mórulas, cinco $(2,2 \%)$ blastocistos iniciais. Os números e os percentuais de embriões em estágio mais avançado com 96 horas foram: três (1\%) mórulas, oito $(4 \%)$ blastocistos iniciais, nove (4\%) blastocistos, cinco $(2 \%)$ blastocistos expandidos. Neste grupo, 
apesar de o desenvolvimento inicial ter sido favorável, o desenvolvimento embrionário final in vitro obteve taxas menores que o esperado, em comparação a Behbahanian et al. (2013), que obtiveram taxas de $40 \%$ e $33,3 \%$, correspondentes à mórula e aos blastocistos do ovário contralateral com oócito fresco maturado in vitro. Pode-se sugerir que isso se deveu ao fato de os embriões não conseguirem transpassar a fase materno-zigótica (TMZ) descrita inicialmente (Stitzel; Seydoux, 2007).

Tabela 2. Estruturas embrionárias observadas durante as 96 horas de cultivo in vitro

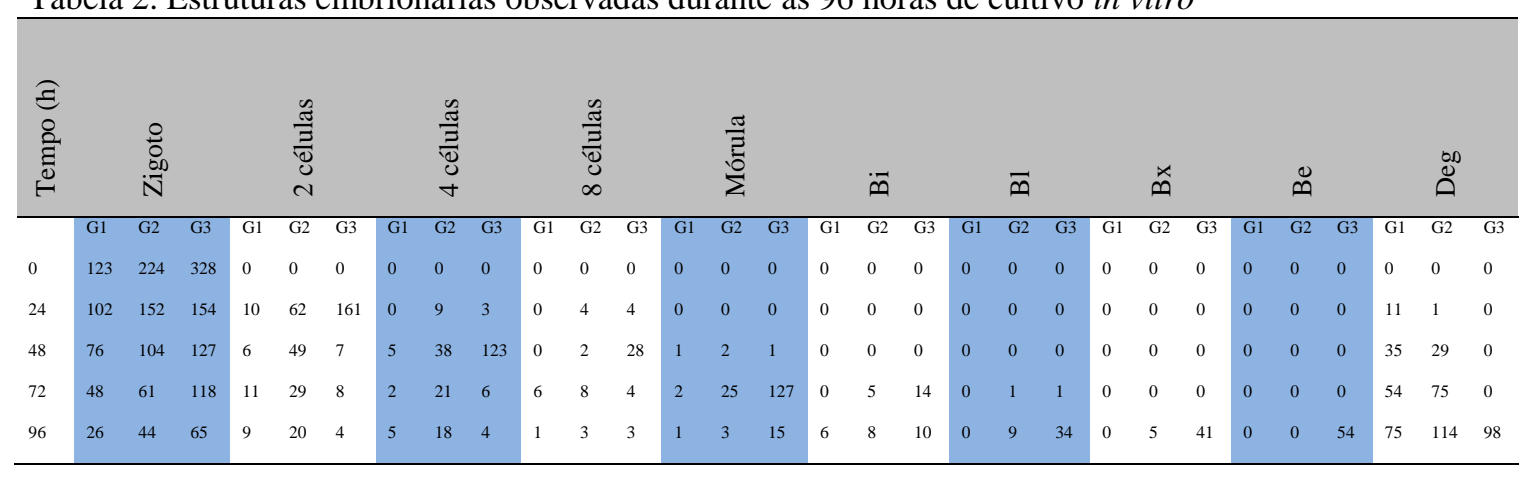

Em G3, às 24 horas, a taxa de clivagem para embriões de duas ou mais células foi 161 (49\%). A taxa de embriões de quatro células em 48 horas foi superior em comparação aos demais grupos, $152(46 \%)$. Os dados referentes a 72 horas demonstraram $123(37,5 \%)$ mórulas, 14 $(4,3 \%)$ blastocistos iniciais, um $(0,3 \%)$ blastocisto, um $(0,3 \%)$ blastocisto expandido. Às 96 horas, encontraram-se taxas de $15(4,6 \%)$ mórulas, $10(3 \%)$ blastocistos iniciais, 34 $(10,4 \%)$ blastocistos, $41(12,5 \%)$ blastocistos expandidos, $54(16,5 \%)$ blastocistos eclodidos (Tab. 2). Esse resultado demonstra que o G3 apresentou as melhores taxas de desenvolvimento in vitro. Isso é algo que já se esperava, uma vez que a maturação in vivo fornece melhores subsídios para os oócitos continuarem o seu desenvolvimento embrionário (Chen et al., 2001).

Para as taxas de clivagem com 24 horas, o G1 $(8 \%)$ diferiu significativamente dos G2 (32\%) $(\mathrm{P}<0,1)$ e $\mathrm{G} 3(49 \%)(\mathrm{P}<0,05)$. No entanto, não houve diferença significativa entre G2 e G3 $(\mathrm{P}>0,05)$ (Fig. 1). Observou-se que, no G1, houve um atraso no desenvolvimento no período avaliado. Contudo, como não houve diferença entre G2 e G3, pode-se considerar que a maturação in vitro apresentou a mesma qualidade encontrada na maturação in vivo quando se observa o desenvolvimento embrionário inicial
(Fig. 1). Entende-se que os oócitos provenientes de ovários vitrificados podem sofrer ações que prejudicam o seu desenvolvimento celular, por lesões nas comunicações com as células do cumulus (Luciano et al., 2009; Zhou et al., 2010).

Nagai et al. (2006) demonstraram uma disfunção mitocondrial e fragmentação em oócitos de camundongos após vitrificação e aquecimento. Eles concluíram que uma distribuição mitocondrial anormal nos oócitos seria uma das causas do atraso no desenvolvimento embrionário, o que foi comprovado também na espécie suína (Shy et al., 2007). Lowther et al. (2009) relataram que a ruptura do retículo endoplasmático durante a vitrificação de oócitos de ratos e deficiências em fatores envolvidos na reorganização dele durante a maturação de oócitos poderiam contribuir para o baixo potencial de desenvolvimento in vitro.

Já para as taxas de desenvolvimento em blastocistos com 96 horas, todos os tratamentos diferiram significativamente $(\mathrm{P}<0,05)$, demonstrando que, em ordem crescente, os melhores resultados de blastocistos após maturação oocitária e fertilização in vitro foram G3 (46\%), G2 (11\%) e G1 (6\%) (Fig. 2). 


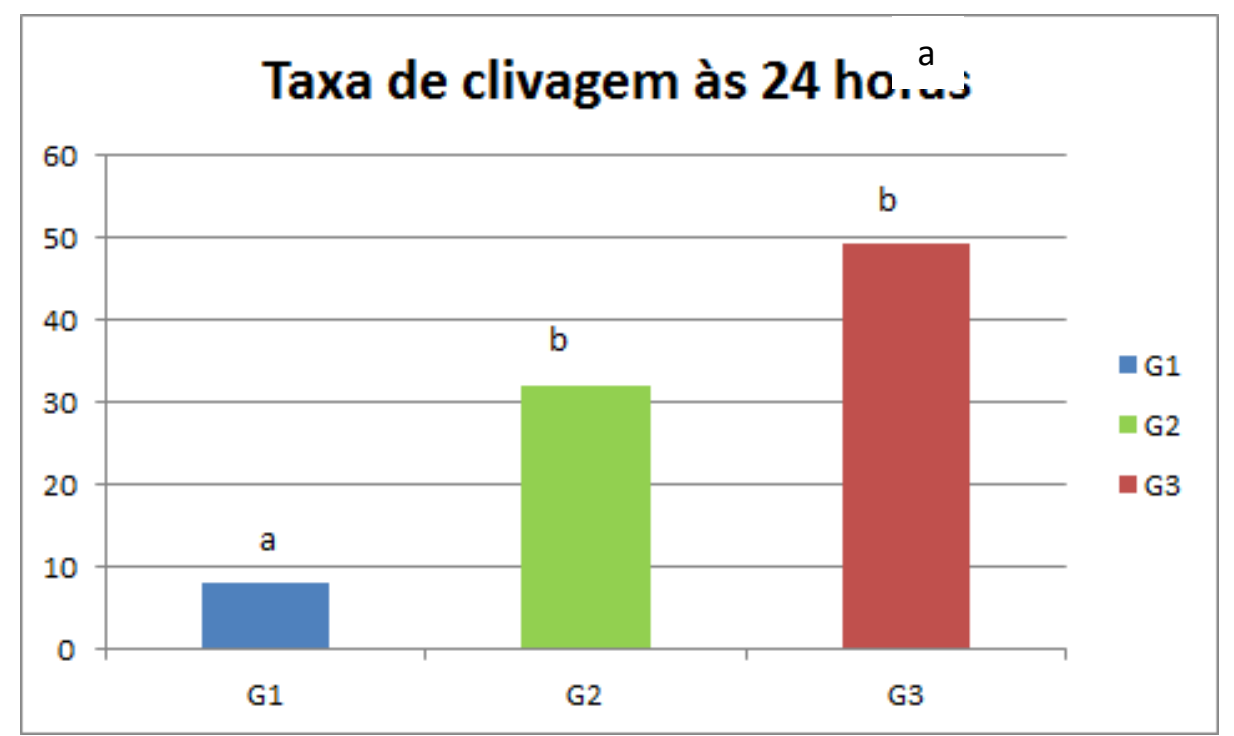

Figura 1. Comparação entre as taxas de clivagem em $\%$ em $24 \mathrm{~h}$ dos diferentes grupos. Análise estatística: G1 x G2 (P=0,0909); G1 x G3 (P=0,05); G2 x G3 (P=0,4345).

${ }^{\mathrm{ab}}$ Letras diferentes - Diferenças significativas entre os tratamentos G1 e G2 $(\mathrm{P}<0,1) \mathrm{G} 1$ e G3 $(\mathrm{P}<0,05)$.

${ }^{\mathrm{bb}}$ Letras iguais - Não houve diferença significativa entre os tratamentos $(\mathrm{P}>0,05)$.

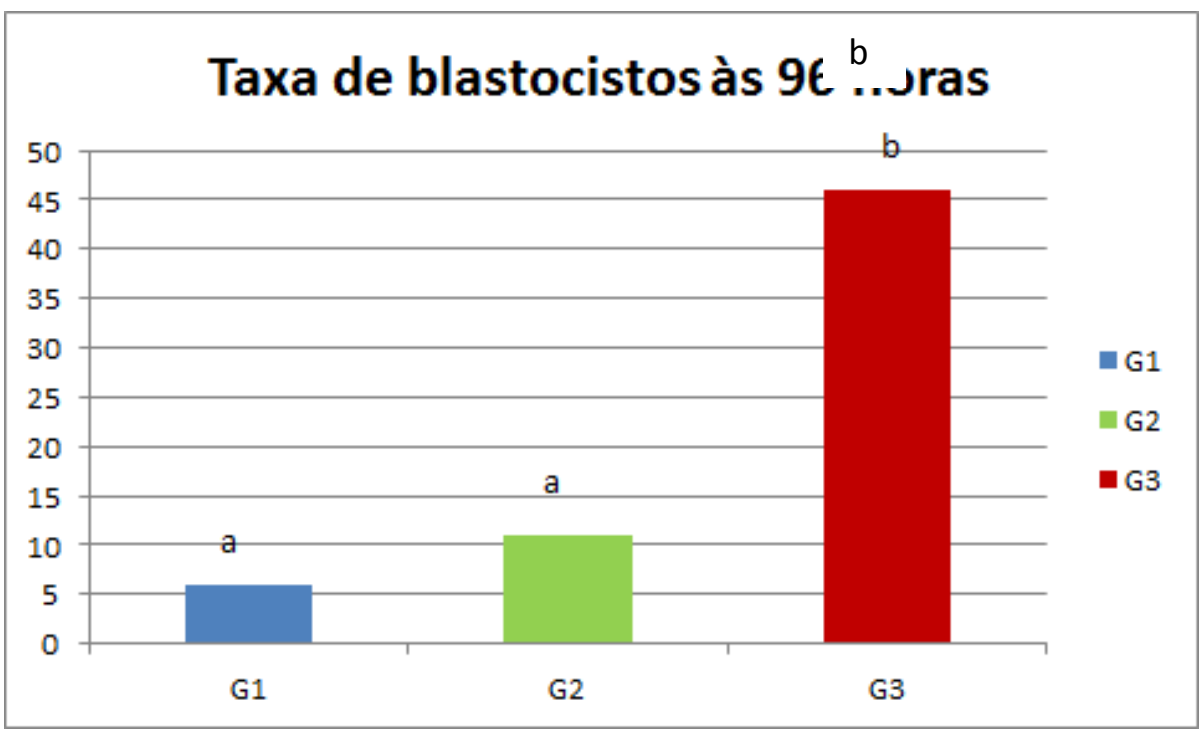

Figura 2. Comparação entre as taxas de blastocistos em $\%$ com $96 \mathrm{~h}$ nos diferentes grupos. Análise

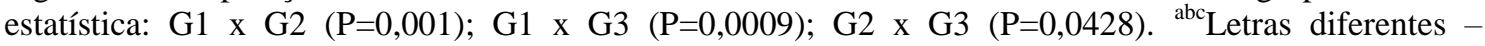
Diferenças significativas entre os tratamentos $(\mathrm{P}<0,05)$.

Paim (2015), em seu trabalho sobre efeitos de diferentes concentrações de crioprotetores na vitrificação dos oócitos imaturos e desenvolvimento embrionário por partenogênese de ratos Wistar, utilizou-se de meios de maturação similares aos que foram utilizados no presente estudo, obtendo resultados para taxa de mórula de $1,8 \%$. No presente estudo, foram observadas, para os grupos G1 e G2, taxas de $6 \%$ e $11 \%$ de blastocistos, respectivamente. Wang et al. (2012), após descongelar tecido ovariano e cultivar folículos pré-antrais (secundários) com maturação dos oócitos, obteve maiores taxas de blastocistos $(24,2 \%)$ quando comparadas às taxas do G1 (6\%) deste estudo. Entretanto, seus resultados para a produção de blastocistos obtidos de oócitos a fresco foram semelhantes aos aqui apresentados: G3 (46\%). 


\section{CONCLUSÕES}

Conclui-se que a técnica de vitrificação de ovários de camundongos é uma alternativa para salvaguardar o patrimônio genético de linhagens que não respondem a nenhum protocolo de criopreservação, já que foi obtida produção de oócitos viáveis pelos resultados de maturação in vitro e fertilização in vitro. No entanto, a vitrificação pode causar atrasos na maturação e impedir o desenvolvimento e a sobrevivência embrionários.

\section{AGRADECIMENTOS}

Os autores agradecem ao Mestrado Profissional em Ciência em Animais de Laboratório e ao Instituto de Ciência e Tecnologia em Biomodelos.

\section{REFERÊNCIAS}

AMORIM, C.A.; CURABA, M.; LANGENDONCKT, A.V.; DOLMANS, M.M.; DONEZ, J. Vitrification as an alternative means of cryopreserving ovarian tissue. Reprod. BioMed., v.23, p.160-186, 2011a.

AMORIM, C.A.; DAVID, A.; DOLMANS, M.M.; CAMBONI, A. DONNEZ, J.; VAN LANGENDONCKT, A. Impact of freezing and thawing of human ovarian tissue on follicular growth after long-term xenotransplantation. $J$. Assist. Reprod. Genet. v.28, p.1157-1165, 2011 b.

BEHBAHANIAN, A.; EIMANI, H.; ZEINALI, B.; VALOJERDI, M. R.; YAZDI, P.E. et al. A. In vitro maturation, fertilization and embryo culture of oocytes obtained from vitrified autotransplanted mouse ovary. Int. J. Fertil. Steril., v.6, p.278, 2013.

BYERS, S.L.; PAYSON, S.J.; TAFT, R.A. Performance of ten inbred mouse strains following assisted reproductive technologies (ARTs). Theriogenology, v.65. p.1716-1726, 2006.

CHEN, S.U.; LIEN, Y.R.; CHENG, Y.Y.; et al. Vitrification of mouse oocytes using closed pulled straws (CPS) achieves a high survival and preserves good patterns of meiotic spindles, compared with conventional straws, open pulled straws (OPS) and grids. Hum. Reprod., p.16, p.2350-2356, 2001.
CRYOPRESERVATION of mouse Germplasm. São Paulo: CEMIB / Universidade Estadual de Campinas, 2012. 38p. (Apostila do $2^{\circ}$ curso criopreservação de germoplasma de camundongos).

DINNYES, A.; WALLACE, G.A; RAIL, W.F. Effect of genotype on the efficiency of mouse embryo cryopreservation by vitrification or slow freezing methods. Mol. Reprod. Devel., v.40, p.429-435, 1995.

FRAJBLAT, M.; AMARAL, V.L.L. Biotécnicas reprodutivas na produção de animais geneticamente modificados para pesquisa biomédica. Rev. Bras. Reprod. Anim., v.41, p.103-104, 2017.

LOWTHER, K.M.; WEITZMAN, V.N.; MAIER, D.; MEHLMANN, L.M. Maturation, fertilization, and the structure and function of the endoplasmic reticulum in cryopreserved mouse oocytes. Biol. Reprod., v.81, p.147-154, 2009.

LUCIANO, A.M.; CHIGIONI, S.; LODDE, V.; FRANCIOSI, F. et al. Effect of different cryopreservation protocols on cytoskeleton and gap junction mediated communication integrity in feline germinal vesicle stage oocytes. Cryobiology, v.59, p.90-95, 2009.

MULLEN, S.F.; CRITSER, J.K. The science of cryobiology. Cancer Treatment Res. v.138, p.83109, 2007.

NAGAI, S.; MABUCHI, T.; HIRATA, S.; HIRATA, S.; SHODA, T.; KASAI, T.; YOKOTA, S.; HOSHI, K. Correlation of abnormal mitochondrial distribution in mouse oocytes with reduced developmental competence. Tohoku J. Exp. Medic., v.210, p.137-144, 2006.

ONOS, K.D.; RIZZO, S.J.S.; HOWELL, G.R.; SASNER, M. Toward more predictive genetic mouse models of Alzheimer's disease. Brain Res. Bull., v.122, p.1-11, 2016.

PAIM, L.M.G. Efeitos da vitrificação de complexos cumulus oócito imaturos de Rattus norvegicus utilizando diferentes concentrações de crioprotetores e tempos de exposição sobre a maturação nuclear e desenvolvimento embrionário, 111f. 2015. Dissertação (Mestrado em Ciências da Saúde) - Universidade Federal de Ciências da Saúde de Porto Alegre, Porto Alegre, RS. 
SALEHNIA, M.; TÖHÖNEN, V.; ZAVAREH, S.; INZUNZ, J. Does cryopreservation of ovarian tissue affect the distribution and function of germinal vesicle oocytes mitochondria? BioMed Res. Int., p.1-8, 2013.

SHI, L.Y.; JIN, H.F.; KIM, J.G.; KUMAR, B.M. Ultra-structural changes and developmental potential of porcine oocytes following vitrification. Anim. Reprod. Sci., v.100, p.128140, 2007.

STITZEL, M.L.; SEYDOUX, G. Regulation of the oocyte-to-zygote-transition. Science, v.316, p.407-408, 2007.

SZTEIN, J.M.; VASUDEVAN, K.; RABER, J. Refinements in the cryopreservation of mouse ovaries. J. Am. Assoc. Lab. Anim. Sci., v.49, p.420-422, 2010.
WANG, X.; CATT, S.; PANGESTU, M.; TEMPLE-SMITH, P. Successful in vitro culture of pre-antral follicles derived from vitrified murine ovarian tissue: oocyte maturation, fertilization, and live births. Reproduction, v.141, p.183-191, 2012.

ZHOU, X.L.; AL NAIB, A.; SUN, D.W.; LONERGAN, P. Bovine oocyte vitrification using the Cryotop method: effect of cumulus cells and vitrification protocol on survival and subsequent development. Cryobiology, v.61, p.66-72, 2010. 